\title{
Intercultural Wonderment: Short Term Study Abroad
}

\author{
Kayla DeMuth ${ }^{1}$, Laura Landry Meyer ${ }^{1}$, Justin Newcomb ${ }^{1}$ \& Susan Peet ${ }^{1}$ \\ ${ }^{1}$ School of Family and Consumer Sciences, Bowling Green State University, Bowling Green, Ohio, USA \\ Correspondence: Kayla DeMuth, School of Family and Consumer Sciences, Bowling Green State University, Bowling \\ Green, Ohio, USA. Tel: 419-889-3812. E-mail: kdemuth@bgsu.edu
}

Received: September 22, 2019

Accepted: October 24, 2019

Online Published: November 24, 2019

doi:10.5430/irhe.v4n4p1

URL: https://doi.org/10.5430/irhe.v4n4p1

\begin{abstract}
The proliferation of study abroad opportunities on college campuses has necessitated a deeper investigation of the impacts derived from participation. The concept of intercultural wonderment focuses on how individuals perceive themselves in an international culture. This concept guided embedded assignments and analysis of assignment responses for a short-term study abroad experience for human development and family studies students to Italy. Intercultural wonderment is a relatively new concept that has potential to guide future research and practice. Results from this exploration using the lens of intercultural wonderment are presented based on a thematic analysis. Conclusions indicate that the intercultural wonderment lens can strengthen cultural awareness and enhance intercultural competency. By noting students' perceptions of their experiences outside their comfort zones, study-abroad experiences can target and foster global learning and development outcomes.
\end{abstract}

Keywords: short-term study abroad, intercultural wonderment, cultural cognizance, student reflections

\section{Introduction and Review of Literature}

Intercultural wonderment is a relatively new term that has emerged in the research literature. The concept of intercultural wonderment focuses on how individuals perceive themselves in an international culture. Engberg and colleagues (2016) coined the concept of intercultural wonderment as "a more nuanced understanding of intercultural immersion by examining the extent to which a study abroad program actively engages students with the host country and encourages them to step outside their comfort zones" (p. 23). The degree to which students feel comfortable being culturally uncomfortable is an effective lens to consider, especially with short term study abroad experiences. As an engagement strategy, short term study abroad experiences can strengthen cultural awareness and enhance the development of intercultural competency (Engberg \& Jourian, 2015).

Immersion outside of one's cultural comfort zone allows the exploration of behaviors, communication patterns, and rituals extending a classroom experience. Understanding globalization, looking at the world through a larger lens, and having cultural competence involve knowledge and skills that college graduates should have as they move into the world of work (Perry, Stoner, \& Tarrant, 2013; Tarrant, 2010). Short-term study abroad experiences enhance the ability of students to develop a sense of globalization and enhance awareness of cultural diversity (Wooldridge, Peet, \& Landry-Meyer, 2018). Short term study aboard are curriculum-based experiences that can increase cultural sensitivity beyond a 'vacation visit' to a location (Bloom \& Miranda, 2015). Effective short-term study abroad experiences prepare and debrief students, plan and maintain on-site curricular-based communication, and are guided by research and theory (Wooldridge, Peet, \& Landry-Meyer, 2018). Using a conceptual lens, such as intercultural wonderment contributes to an effective planning, implementation, and evaluation of the experience for students and faculty.

A sense of cultural competence is especially relevant for students who wish to work with families and individuals across the lifespan in human development and family studies including childhood education. Human development and family studies (HDFS) focuses on lifespan development of individuals within a family context using a strengths-based approach. HDFS follows certain standards including content areas provided by the National Council of Family Relations which promote cultural cognizance, gender fairness, and special need awareness (Landry-Meyer \& Roe, 2013). Intercultural wonderment is relevant to HDFS because it deals with individual development from global learning perspective. An effective strategy in HDFS to increase cultural cognizance is a study abroad experience. This strategy in an education program can strengthen cultural awareness and the development of intercultural competency (Engberg \& Jourian, 2015). 
Using the conceptual definition of intercultural wonderment, embedded assignments with open-ended questions explored cultural immersion outside a college student's zone of familiarity. Intercultural wonderment guided reflection assignment prompts and subsequently a thematic analysis. The purpose of this paper is to present themes based on the cultural immersion experience ad to look into the effects of wonderment on someone's study abroad experience and development.

\section{Method}

Participants were 12 students who attended a short-term study abroad experience to Italy for 17 days in 2019 . Students were primarily female, with some travel outside of the U.S. and the desire to enhance global knowledge and awareness. Students were from a midwestern university with the majority studying human development and family studies and one early childhood education student. The authors participated in the short-term study abroad experience. Student reflection assignments were embedded in the course workbook/reflection journal guided by intercultural wonderment. Approximately after each destination location, students wrote a reflection about the experience. There was a total of nine required journal reflections. Each of the 12 students submitted 9 journal reflections for a total of 108 reflections that were included. As a data source, student reflections in assignments document their learning experiences and reflect on the learning process and outcomes (Litke, 2002). A strength of the use of student reflections is that they provide a record of reflective thinking over time and can provide a rich record of experience specific to the intercultural wonderment prompts.

\subsection{Measures}

The operationalization of intercultural wonderment was based on the authors' discussion and review of the literature. Using the operationalization, reflection prompts were developed to urge students to contemplate various aspects of intercultural wonderment. Reflection prompts used the acronym of W-O-N-D-E-R to operationalize intercultural wonderment. The operationalization and question prompt are outlined next.

\section{W: How did this location help WRITE your life story?}

The W prompt focused specifically on the intercultural wonderment aspects of meaning-making, self-authorship, and identity. Students were prompted to think about how the experiences at a specific location had meaning to them. What did you encounter that impacted you? Your identity? Mostly this prompt was about self-authorship. Self-authorship is defined by Robert Kegan as an "ideology, an internal personal identity, a self-authorship that can coordinate, integrate, act upon, or invent values, beliefs, convictions, generalizations, ideals, abstractions, interpersonal loyalties, and intrapersonal states" (Engberg et al., 2016, p.23). This prompt focused on how students created meaning, integrated the experience into their identity or felt a sense of self-authorship.

\section{O: What was an $\mathrm{OH}-\mathrm{WOW}$ experience?}

The Oh-Wow experience prompt attempted to identify a sense of mindfulness. The intent was to have students reflect if they were aware of the present moment and being immersed in another culture. There was an attempt for students to identify some cultural aspects at a location that made them mindful about American culture. Specific questions were: What did you encounter that may you feel present, in-the-moment? How did the experience increase your awareness? Students were prompted to think about sights, sounds, smells, feelings.

\section{N: What NOT ABOUT YOU experience did you try \& encounter?}

Prompts focused on what ways did you view the world from another's point of view and the impact of that view. In what ways did you view the world from another's point of view? What type of impact did this 'other' point of view have on you? The concepts of flexibility vs rigidity, comfort zone, cultural cognizance and cognitive disequilibrium were embedded with this prompt. For instance, cognitive equilibrium is a state of mental balance most easily achieved through assimilation, a process of interpreting new experiences by referencing preexisting ideas. Cognitive disequilibrium is a concept embedded in intercultural wonderment. Specifically, 'not about you' referred to cognitive equilibrium or a state of mental balance most easily achieved through assimilation, a process of interpreting new experiences by referencing preexisting ideas (Engberg, et al., 2016). Students were encouraged to think about cultural behaviors and communication in addition to the simple exploration of their motivation to explore an unfamiliar setting or food or experience.

D: How did you DEAL with being comfortable with being uncomfortable?

This prompt highlights that spirit of intercultural wonderment about being immersed in another culture and recognizing and respecting the uniqueness of the culture. Experiencing difference can contribute to being uncomfortable for some students. Immersing oneself in another culture encourages students to step outside of 
established comfort zones. The reflection question about how did you try to become comfortable with being uncomfortable recognizes the intercultural wonderment concepts of intercultural maturity, comfort zone, and flexibility vs rigidity. There was an encouragement for students to view themselves in a global context.

\section{E: What aspect of this location encouraged your curiosity about families living here?}

This reflection question focused specifically on the intercultural wonderment aspects of intercultural maturity, cultural cognizance, and mindfulness. As future professionals who will work with children and families, this question was identified to have students apply content knowledge in an cultural context. Individual reflection about families engages students with another culture through analysis based on their current lived and educational experiences. Specific questions included: What experiences created a desire to learn more? In what ways were you inquisitive and observant of the culture?

\section{R: How did you respect the culture?}

This prompt focused on actions, attitudes, thoughts that students demonstrated that respected the value for another cultures. Specific intercultural wonderment components included cultural cognizance and mindfulness. This specific prompt was developed to explore if students would be able to recognize and respect cultural norms when in contrast to those in the United States. Specific questions included: What actions, attitudes, thoughts did you have that demonstrated value for other cultures? Were you able to observe others based on an awareness of diverse worldviews?

\subsection{Analysis}

At the completion of the study abroad experience, student reflection responses to embedded assignments were collected. Each student was assigned a code number. Reflections were organized based on the components of intercultural wonderment acronym W-O-N-D-E-R. Two of the authors coded the reflections with a third author involved in establishing inter-rater reliability. Using a random selection of students and prompts, discrepancies were identified and resolved. Following initial selection with the three authors for interrater reliability, $100 \%$ agreement was reached with subsequent coding by the two authors.

Codes were developed based on content, then themes were identified using the broad categories. Entire segments of reflections were coded based on the acronym W-O-N-D-E-R. Based on the codes, themes emerged. Themes represent a level of patterned response (Braun \& Clarke, 2006). Thematic analysis "involves the search for and identification of common threads that extend across [narratives]" (Vaismoradi, Turunen, \& Bondas, 2013, p. 400). Themes were reviewed at semantic, explicit, surface-level level intended to show patterns in attempt to interpret (Braun \& Clarke, 2006). The analysis was based on selecting pieces of content specific to intercultural wonderment during a short-term study abroad trip.

\section{Results}

Results are organized based on frequencies of themes based on the acronym W-O-N-D-E-R. The purpose was to explore the usefulness of intercultural wonderment as a lens for learning during a short-term study abroad experience. Overall, results indicate that using intercultural wonderment to guide reflection prompts was useful. The frequencies reflect 108 responses based on the nine embedded assignments for the 12 students. Frequency results are presented based on the acronym organization and coding.

\section{W: How did this location WRITE your life story?}

Overwhelmingly, students felt a sense of belonging. Throughout the reflections, this theme was mentioned 50 times. Some descriptions of these sense of belonging feeling included feeling comfortable, being at peace with the experience, an acceptance of differences, self-awareness, awareness of group dynamics/getting to know members and contemplation about career goals. Within this prompt, students mentioned a sub theme of having the chance to explore 35 times. Notations about experiencing new things, having curiosity, testing one's self and having a sense of adventure were the most common.

With this exploration, students were cognizant of the historical context of the location. There was a new understanding of 'old' concepts and historical contexts and an appreciation and respect for history that was cited 29 times. Another subtheme cited 28 times inferred a bigger picture of one's life's story, values and beliefs, sense of materialism, religion, personal philosophies, education, women's rights/social awareness. As the prompt focused on the components of self-authorship, meaning-making and intercultural maturity, these findings seemed congruent. For instance, one student stated:

Traveling abroad with other students and mentors has by far been the best experience of my life. I have memories that are hard to communicate with those who have never experienced such an adventure. The 
typical person asks about the food and the events I most enjoyed, but they are missing the bigger picture. The bigger picture is included in my identity.

\section{O: What was an $\mathrm{OH}-\mathrm{WOW}$ experience?}

Students made note of the diversity of people 49 times. Comments and reflections noted specific individual and groups with categories ranging from size of crowd to social class to religious clothing to ability and access. The within group diversity reinforced a sense of mindful immersion and noting the various aspects of life. Another sub category cited 35 times was variety of transportation used. A mindful immersion of the contrast to transportation utilized at 'home'. Specific comments were made about utilizing trains, walking, and boating. There was a mindful contrast to American culture. Another in-the-moment theme was the architecture (29 times) and aesthetic beauty noted 27 times as an oh-wow experiences. Many students noted being in awe of the characteristics of the location, the history, intricacy with design of buildings as well as the vistas, towns, cleanliness of locations and pride of place.

$\mathrm{N}$ : What NOT ABOUT YOU experience did you try and encounter?

Students noted 46 times their general awareness of cultural diversity through observation. Specific examples included others' reactions, struggles, passions; consequences of tourism on locals, water pollution, social issues, economic issues, and meeting new people. These observations are examples of cultural awareness based on specific location and noting the uniqueness. A sub theme described 28 times was imaging life as someone encountered on the Italy experience, like living in the location. These reflections note a type of assimilation of a process of explaining new experiences by referencing what is known based on past cultural experiences.

Students noted 24 times the concept of respecting diversity. Specific examples included accepting values despite not sharing similar values, religious tolerance, searching for authentic cultural experiences, and being mindful of others' needs. In the context of openness to new ideas, a student wrote:

When comparing my attitude and sense of openness before the experience and after, I am more outgoing and accepting. There were several times throughout the experience when I felt uncomfortable, however, I breathed and kept going.

D: How did you DEAL with being comfortable with being uncomfortable?

Coping with intercultural wonderment by recognizing and respecting the uniqueness of the culture is an important component of study abroad experiences. The most frequent coping strategies noted 34 times was self-determination and self-talk to get through a moment. Lack of personal space was noted several times referencing being a member of a study abroad group that required the majority of the day being with others. Another frequently noted strategy (24 times) was about mindfulness through meditation, imaging, acting calm, using beauty (artwork, views). This strategy was followed by being aware and alert, in-the-moment, open-minded - strategies identified 21 times. Themes highlighted importance of comfort zone, and flexibility vs rigidity.

E: What aspect of this location encouraged your curiosity about families living here?

As students were primarily from a HDFS background, observing family interactions was the dominant theme cited 44 times. Specific contexts of interactions were gender roles, family dinner, norms, childcare, and extended family roles and interaction. Similar to this dominant theme, family economics was next frequently cited 37 times. Most comments in this theme focused on socioeconomic status, insurance, expensive stores, community, policies, family owned businesses, small/big city, poverty rate, homeless, and community resources. The concept of physical accessibility was noted 30 times with specific comments about lack of universal design, transportation challenges, safety and space constraints.

\section{$\underline{\mathrm{R}: \text { How did you respect the culture? }}$}

The most frequently cited way to respect culture was through mannerisms (45 times). Students indicated that they displayed respect by eating/trying various foods, politeness, appreciation, support for rituals and traditions, general hospitality, greetings, and language. Reflections noted a mindfulness in students about cultural attitudes and expectations. Another theme was an increase in cultural awareness cited 15 times. Specific example was being attentive of how personal experiences impact interpretation. Reflections included phrases about putting myself in their shoes and the need to understand Catholicism and its context/influence in communities.

There was also a sense of flexibility noted 13 times. This flexibility was classified as being open-minded and a desire to learn new things, ask questions as well as respecting diverse worldviews including different people and gender roles. For instance, one student noted: 
I increased my knowledge of cultural worldview framework. Touring Italy and seeing significant pieces of art and structures have developed my understanding of the complex elements important to this culture. The structures and art are significant to the history by showing creation and telling stories. The religious and family view in Italy are strong and the culture values... are significant.

\section{Discussion and Conclusion}

The analysis presented in this paper attempts to systematically document learning based on the lens of intercultural wonderment. Using student reflections based on embedded course assignments has been implemented by others with success (Litke, 2002). Results have implications for those who are interested in understanding student learning in study abroad contexts and how to maximize effectiveness of study abroad experiences. Results indicate that students developed a deeper understanding and openness to new ideas, interpretations of observations, critical thinking, and accessibility. Intercultural wonderment incorporates the concepts of mindful wonderment, mindfulness, self-authorship, meaning-making, and intercultural maturity through first-hand experiences. The positive discomfort that comes with intercultural wonderment can structure study abroad components and can reduce student anxieties by knowing the perceptions of students in unfamiliar settings.

Using research and evidence-based information from a student perspective can improve cultural learning opportunities. These results show that intercultural wonderment can strengthen cultural awareness and the development of intercultural competency. By noting what experiences have engaged students outside their comfort zones, study-abroad experiences can target community aspects and foster a host of global learning and development outcomes. A contribution of this study is the usefulness of intercultural wonderment as a guiding lens for planning, implementing, and evaluating short-term study abroad experiences. Using the concept allows the translation of learning outcomes through workbook reflection prompts. Reflection is an integral component of engaged learning for students and use of student reflections was a useful 'evaluation' tool of the course (Litke, 2002). Additionally, the prompts organized with the acronym offers a useful coding structure for replicability.

Overall, student reflections are congruent with intercultural wonderment occurring during a short-term study abroad experience. Intercultural wonderment is all about the diversity and complexities of human experience. With daily interactions becoming more diverse in culture, customs, language and other characteristics, it is important for students and professionals to have a sense of cultural competence. This research is for and about people and entail complexities attributed to working with people. Multicultural relations involves a continuous exchange between all entities and one must recognize their own contributions/identity in it all. The immersion outside of one's cultural comfort zone allowed students to explore behaviors, communication patterns, and rituals. Understanding globalization, looking at the world through a larger lens, and having cultural competence involve knowledge and skills that college graduates should have as they move into the world of work (Perry, Stoner, \& Tarrant, 2013; Tarrant, 2010).

\section{Limitations}

For the exploration of the usefulness of intercultural wonderment as a guiding concept, a short-term study abroad trip consisting of 12 students primarily female and from HDFS background was used. The sample is limiting in the ability to generalize. The inherent strength is the value of the intercultural wonderment concept as the potential to guide future study abroad experiences and student engagement.

Another limitation is the use of reflections. Some students may lack reflective and writing skills or be apprehensive about disclosing perceptions in an assignment to be viewed and graded by others.

\section{References}

Bloom, M., \& Miranda, A. (2015). Intercultural sensitivity through short-term study abroad. Language and Intercultural Communication, 15(4), 567-580. https://doi.org/10.1080/14708477.2015.1056795

Braun, V., \& Clarke, V. (2006). Using thematic analysis in psychology. Qualitative Research in Psychology, 3, 77-101. https://doi.org/10.1191/1478088706qp063oa

Engberg, M., Jourian, T., \& Davidson, L. (2016). The mediating role of intercultural wonderment: connecting programmatic components to global outcomes in study abroad. Higher Education, 71, 21-37. https://doi.org/10.1007/s10734-015-9886-6

Landry-Meyer, L., \& Roe, J. (2013). Linking teaching methods and assessment to the developmental needs of family science students. Family Science Review, 18(1), 117-133. https://doi.org/10.26536/FSR.2013.18.01.07

Litke, R. A. (2002). Do all students "get it?" Comparing students' reflections to course performance. Michigan Journal of Community Service Learning, 8(2), 27-34. 
Lopes-Murphy, S. A., \& Murphy, C. G. (2016). The influence of cross-cultural experiences and location on teachers' perceptions of cultural competence. Journal of the Scholarship of Teaching and Learning, 16(3), 57-71. https://doi.org/10.14434/josotl.v16i3.19331

Perry, L., Stoner, L., \& Tarrant, M. (2013). More than a vacation: Short-Term study abroad as a critically reflective, transformative learning experience. Creative Education, 3(5), 679-683. https://doi.org/10.4236/ce.2012.35101

Tarrant, M. A. (2010). A conceptual framework for exploring the role of studies abroad in nurturing global citizenship. Journal of Studies in International Education, 14, 433-451. https://doi.org/10.1177/1028315309348737

Vaismoradi, M., Turunen, H., \& Bondas, T. (2013). Content analysis and thematic analysis: Implications for conducting a qualitative descriptive study. Nursing and Health Sciences, 15, 398-405. https://doi.org/10.1111/nhs.12048

Wooldridge, D., Peet, S., \& Landry-Meyer, L. (2018). Transforming professionals through short-term study abroad experiences. Delta Kappa Gamma Bulletin, 84(4), 31-36. 